\title{
In vitro Cytotoxic, Membrane Stabilizing and Thrombolytic Activities of Polygonum glabrum Willd
}

\author{
Mohammad Firoz Khan ${ }^{1}$, Sikder Nahidul Islam Rabbi ${ }^{1}$, Fahima Aktar ${ }^{2}$ and \\ Md. Hassan Kawsar ${ }^{1}$ \\ ${ }^{1}$ Department of Pharmacy, State University of Bangladesh, Dhaka-1205, Bangladesh \\ ${ }^{2}$ Department of Pharmaceutical Chemistry, Faculty of Pharmacy, University of Dhaka, Dhaka-1000, Bangladesh
}

Received: March 31, 2014;

Accepted: June 17, 2014;

Published (Web): July 23, 2014

\begin{abstract}
The crude methanol extract of leaves of Polygonum glabrum Willd and its Kupchan fractions were screened for cytotoxic, membrane stabilizing and thrombolytic activities. Among all fractions, the crude methanol extract showed significant cytotoxic activity having $\mathrm{LC}_{50}$ value $0.74 \pm 0.045 \mu \mathrm{g} / \mathrm{ml}$. Moreover, in hypotonic solution- and heat- induced conditions, the crude methanol extract inhibited hemolysis of human erythrocyte by $79.21 \pm 0.44 \%$ and $84.87 \pm 0.23 \%$, respectively as compared to $71.9 \pm 0.73 \%$ and $42.12 \pm 0.37 \%$ demonstrated by the standard acetyl salicylic acid. On the other hand, in thrombolytic activity assay the methanol extract demonstrated highest clot lysis value of $35.17 \pm 0.42 \%$.
\end{abstract}

Key words: Polygonum glabrum, cytotoxic, membrane stabilizing and thrombolytic.

\section{Introduction}

The plant Polygonum glabrum willd (FamilyPolygonaceae, Common Name- Denseflower knotweed) is an erect, glabrous herb, $70-100 \mathrm{~cm}$ in height. Annual herb, dilated at nodes, rarely branched (Jamal et al., 2011). $P$. glabrum have been used as folk medicine and as ingredient in various Ayurvedic preparations (Jamal et al., 2011). A decoction of the plant has been used as a foot and leg soak in the treatment of rheumatism (Shiddamallayya et al., 2010; Khare et al., 2007). The leaves of $P$. glabrum are used as anthelminthes and antimalarial agent in Sudan (Hashim and Kamali, 2009). The leaves and roots are used as colic and febrifuge in piles and jaundice (Shiddamallayya et al., 2010). In South India the leaf extract of $P$. glabrum are used to treat dysentery (Soudahmini et al., 2005).

Previous phytochemical studies of $P$. glabrum revealed that the chloroform soluble fraction contains alkaloids, carbohydrates and flavonoids (Sivakumar et al., 2011).

Since this plant has important medicinal properties and based on its availability, therapeutic value and the degree of research work, which is not done mostly in earlier the present study has been undertaken.

\section{Materials and Methods}

Plant materials: The leaves of $P$. glabrum were collected from Khulna and a voucher specimen of the plant sample has been deposited in the Department of Botany, University of Dhaka for future reference.

Extraction and fractionation: The collected plant parts were sun dried for several days and then oven dried for 24 hours at $40^{\circ} \mathrm{C}$ to facilitate grinding. The powdered whole plant (500 gm) of P. glabrum was extracted with about 1.5 L methanol for 7 days and then filtered through a cotton plug followed by whatman filter paper number 1 . The extract was then concentrated by using a rotary evaporator at reduced temperature $\left(40-45^{\circ} \mathrm{C}\right)$ and pressure. The concentrated methanol extract (ME) was partitionated by modified Kupchan method (Van Wagenen et al., 1993) and the resultant partitionates i.e., methanol extract (ME), petroleum ether (PE), carbon tetrachloride (CT), chloroform (CL) and aqueous (AQ) soluble materials were used for different biological screenings.

Cytotoxic activity: This technique was applied for the determination of general toxic property of the plant extractives using the method of Meyer et al. (1982) and McLaughlin et al. (1998) against Artemia salina in a 1day in vivo assay. Vincristine sulphate was used as positive control. 
Membrane stabilizing activity: The membrane

observed for clot lysis. After incubation, the released fluid was removed and tubes were again weighed to observe the Correspondence to: Md. Hassan Kawsar;.Tel.: 880-2-9854301; E-mail: hassankawsar@yahoo.com

difference in weight after

stabilizing activity of the extractives was assessed by evaluating their ability to inhibit hypotonic solution and heat induced hemolysis of human erythrocytes following the method developed by Omale et al. (2008).

Thrombolytic activity: Whole blood was drawn from healthy volunteers without a history of oral contraceptive or anticoagulant therapy and $1.0 \mathrm{ml}$ of blood was transferred to the previously weighed microcentrifuge tubes and was allowed to clot.

The thrombolytic activity of all extracts was evaluated by the method developed by Daginawala (2006) using streptokinase (SK) as the standard substance. The extract (100 mg) from each plant was suspended in $10 \mathrm{ml}$ of distilled water and it was kept overnight. Then the soluble supernatant was decanted and filtered through a 0.22 micron syringe filter. For clot lysis venous blood drawn from healthy volunteers was distributed in different preweighed sterile microcentrifuge tube $(1 \mathrm{ml} /$ tube $)$ and incubated at $37^{\circ} \mathrm{C}$ for 45 minutes. After clot formation, the serum was completely removed without disturbing the clot and each tube containing the clot was again weighed to determine the clot weight (clot weight $=$ weight of clot containing tube - weight of tube alone).

To each microcentrifuge tube with the pre-weighed clot, $100 \mu 1$ aqueous solution of different partitionates and crude extract was added separately. Then, $100 \mu \mathrm{l}$ of streptokinase and $100 \mu \mathrm{l}$ were separately added to the control tube as positive and negative controls respectively. All tubes were then incubated at $37^{\circ} \mathrm{C}$ for 90 minutes and clot disruption. Difference obtained in weight taken before and after clot lysis was expressed as percentage of clot lysis as shown below:

$\%$ of clot lysis $=($ wt of released clot $/$ clot $w t) \times 100$

Streptokinase (SK): Commercially available lyophilized Alteplase (Streptokinase) vial (Beacon pharmaceutical Ltd) of 15,00,000 IU, was collected and 5 $\mathrm{ml}$ sterile distilled water was added and mixed properly. This suspension was used as a stock from which $100 \mu \mathrm{l}$ (30, $000 \mathrm{IU})$ was used for in vitro thrombolysis.

Statistical Analysis: Three replicates of each sample were used for each assay to facilitate statistical analysis and the values are reported as mean $\pm \mathrm{SD}$.

\section{Result and Discussion}

The methanol extract of P. glabrum as well as different Kupchan partitionates derived from it were subjected to assay for cytotoxic, membrane stabilizing and thrombolytic activities.

The median lethal concentration $\left(\mathrm{LC}_{50}\right)$ of the test samples after 24 hours was obtained by a plot of percentage of the shrimps killed against the logarithm of the sample concentration and the best-fit line was obtained from the graph by means of regression analysis. Among all the partitionates of crude methanol extract of $P$. glabrum, the crude methanol extract exhibited highest lethality having $\mathrm{LC}_{50}$ value $0.74 \pm 0.045 \mu \mathrm{g} / \mathrm{ml}$ (Table 1).

Table 1. $\mathrm{LC}_{50}$ values of standard and different partitionates of $P$. glabrum in brine shrimp lethality bioassay.

\begin{tabular}{cccc}
\hline Test samples & Regression line & $\mathrm{R}^{2}$ & $\mathrm{LC}_{50}(\mu \mathrm{g} / \mathrm{ml})$ \\
\hline VS & $\mathrm{y}=30.79 \mathrm{x}+60.65$ & 0.973 & $0.471 \pm 0.032$ \\
PE & $\mathrm{y}=36.03 \mathrm{x}+22.04$ & 0.851 & $5.97 \pm 0.222$ \\
$\mathrm{CT}$ & $\mathrm{y}=36.64 \mathrm{x}+10.29$ & 0.926 & $2.04 \pm 0.235$ \\
$\mathrm{CL}$ & $\mathrm{y}=42.07 \mathrm{x}+2.511$ & 0.928 & $13.45 \pm 0.155$ \\
ME & $\mathrm{y}=21.74 \mathrm{x}+52.87$ & 0.883 & $0.74 \pm 0.045$ \\
AQ & $\mathrm{y}=35.43 \mathrm{x}+7.798$ & 0.961 & $15.53 \pm 0.065$ \\
\hline
\end{tabular}

$\mathrm{VS}=$ Vincristine sulfate, $\mathrm{PE}=$ Pet ether soluble fraction, $\mathrm{CT}=$ Carbon tetrachloride soluble fraction, $\mathrm{CL}=\mathrm{Chloroform}$ soluble fraction, $\mathrm{ME}=$ Methanol extract, $\mathrm{AQ}=$ Aqueous soluble fraction. 
At concentration $1.0 \mathrm{mg} / \mathrm{ml}$, the different partitionate fractions of $P$. glabrum protected the hemolysis of RBC induced by hypotonic solution and heat as compared to the standard acetyl salicylic acid. The crude methanol extract inhibited $79.21 \pm 0.44 \%$ and $84.87 \pm 0.23 \%$ of hemolysis of $\mathrm{RBC}$ induced by hypotonic solution and heat as compared to $71.9 \pm 0.73 \%$ and $42.12 \pm 0.37 \%$ by acetyl salicylic acid, respectively (Table 2 ).

As a part of discovery of cardio protective drugs from natural resources, methanol extracts of $P$. glabrum was assessed for thrombolytic activity and the results are presented in Table 3. Addition of $100 \mu \mathrm{l} \mathrm{SK}$, a positive control $(30,000 \mathrm{IU})$, to the clots and subsequent incubation for 90 minutes at $37^{\circ} \mathrm{C}$, showed $65.16 \pm 0.48 \%$ lysis of clot. On the other hand, distilled water was treated as negative control which exhibited a negligible percentage of lysis of clot $2.41 \pm 0.27 \%$. The mean difference of in clot lysis percentage between positive and negative control was found statistically very significant. In this study, methanol extract of $P$. glabrum exhibited highest thrombolytic activity $(35.17 \pm 0.42 \%)$.

Table 2. Percentage (\%) inhibition of heat and hypotonic solution induced hemolysis of erythrocyte membrane by standard and different partitionates of $P$. glabrum.

\begin{tabular}{lcc}
\hline \multirow{2}{*}{ Samples } & \multicolumn{2}{c}{ \% Inhibition of hemolysis } \\
\cline { 2 - 3 } & Heat induced & $\begin{array}{c}\text { Hypotonic solution } \\
\text { induced }\end{array}$ \\
\hline CL & $11.78 \pm 0.12$ & $24.63 \pm 0.61$ \\
ME & $84.87 \pm 0.23$ & $79.21 \pm 0.44$ \\
CT & $18.10 \pm 0.15$ & $24.63 \pm 0.32$ \\
PE & $76.60 \pm 0.88$ & $1.48 \pm 0.04$ \\
AQ & $5.43 \pm 0.76$ & $42.47 \pm 0.36$ \\
ASA & $42.12 \pm 0.37$ & $71.9 \pm 0.73$ \\
\hline
\end{tabular}

$\mathrm{CL}=$ Chloroform soluble fraction, $\mathrm{ME}=$ Methanol extract, $\mathrm{CT}=$ Carbon tetrachloride soluble fraction, $\mathrm{PE}=$ Pet ether soluble fraction, $\mathrm{AQ}=$ Aqueous soluble fraction, $\mathrm{ASA}=$ Acetyl salicylic acid.

Table 3. Thrombolytic activity of $P$. glabrum.

\begin{tabular}{cc}
\hline Sample & \% of lysis \\
\hline Blank & $2.41 \pm 0.27$ \\
SK & $65.16 \pm 0.48$ \\
CL & $14.85 \pm 0.08$ \\
ME & $35.17 \pm 0.42$ \\
CT & $15.63 \pm 0.33$ \\
PE & $20.68 \pm 0.51$ \\
AQ & $17.70 \pm 0.12$ \\
\hline
\end{tabular}

$\mathrm{SK}=$ streptokinase, $\mathrm{CL}=$ Chloroform soluble fraction, $\mathrm{ME}=$ Methanol extract, $\mathrm{CT}=$ Carbon tetrachloride soluble fraction, $\mathrm{PE}=$ Pet ether soluble fraction, $\mathrm{AQ}=$ Aqueous soluble fraction .

\section{Acknowledgement}

The authors wish to acknowledge the State University of Bangladesh for providing laboratory facilities.

\section{References}

Daginawala, H.F., Prasad, S., Kashyap, R.S., Deopujari, J.W., Purohit, H.J. and Taori, G.M. 2006. Development of an in vitro model to study clot lysis activity of thrombolytic drugs. Thromb J. 4, 14-18.

EL-Kamali, H.H. 2009. Effect of certain medicinal plants extracts against storage pest, Tribolium castaneum Herbst. Am.-Eurasian J. Sustain. Agric. 3, 39-42.

Jamal, B.D., Avinash, K.R.G., Naganjenulu, R., Jyothi, M.J., Kalishwari, E. and Anvesh, M. 2011. Phytochemical screening and antipyretic activity of root stocks of Polygonum glabrum Willd in rats. Int. J. Pharmacother. 1, $1-4$.

Khare, C.P. 2007. Indian Medicinal Plants: An Illustrated Dictionary, Springer Science \& Business Media, LLC, NY, USA, p. 509.

McLaughlin, J.L., Anderson, J.E. and Lingling, L.R. 1998. The use of biological assays to evaluate botanicals. Drug Info J. 32, 513-524.

Meyer, B.N., Ferrigni, N.R., Putnam, J.E., Jacobsen, L.B., Nichols, D.E. and McLaughlin, J.L. 1982. Brine shrimp: a convenient general bioassay for active plant constituents. Planta Med. 45, 31-34.

Omale, J. and Okafor, P.N. 2008. Comparative antioxidant capacity, membrane stabilization, polyphenol composition and cytotoxicity of the leaf and stem of Cissus multistriata. Afr J. Biotechnol. 7, 3129-3133.

Sivakumar, P.K., Senthilkumar, L. and Praveen, V.J. 2011. Phytochemical studies on Polygonum glabrum (Willd.). Int. J. Pharma Bio. Sci. 2, 169-175.

Shiddamallayya, N., Yasmeen, A. and Gopakumar, K. 2010. Medico-botanical survey of kumar parvatha kukke subramanya, Mangalore, Karnataka. Indian J. Trad. Knowledge 9, 96-99.

Soudahmini, E., Ganesh, M., Senthi, P.L., Madhu, C. and Divakar. 2005. Herbal remedies of Madugga tribes of Siruvani forest, South India. Nat. Prod. Radiance. 4, $492-$ 499.

Van-Wagenen, B.C., Larsen, R., Cardellina, J.H., Randazzo, D., Lidert, Z.C. and Swithenbank, C. 1993. Ulosantoin, a potent insecticide from the sponge Ulosa ruetzleri. J. Org. Chem. 58, 335-337. 